\title{
МОДЕЛИ ВЗАИМООТНОШЕНИЙ СУБЪЕКТОВ ИНВЕСТИЦИОННО- СТРОИТЕЛЬНОГО ПРОЦЕССА И РОЛЬ ПРОЕКТНЫХ ОРГАНИЗАЦИЙ
}

\section{(c) 2019 Мельникова Евгения Сергеевна} аспирант

\section{Санкт-Петербургский государственный экономический университет, Россия, Санкт-Петербург} E-mail: eugenia_kov@mail.ru

В статье рассматривается инвестиционно-строительный процесс и взгляды научного сообщества на определение данного понятия. Систематизированы и определены их полномочия и обязательства субъектов инвестиционно-строительного процесса, а также разработаны и рассмотрены модели их взаимодействия в зависимости от источников инвестиций. Проанализирована важность проектной деятельности и определена роль проектирования в строительной отрасли.

Ключевые слова: строительство, проектирование, проектные организации, инвестиционно-строительный процесс, инвестиционно-строительный проект, субъекты инвестиционно-строительного процесса

Процесс строительства (в широком смысле) является «многоступенчатым» и одним из определяющих экономику государства.

Он включает в себя организационные, финансовые, производственные механизмы, которые, в свою очередь, включают в себя множество видов деятельности: изыскательские, проектные, строительно-монтажные и пусконаладочные и иные виды работ, связанные с созданием, изменением или сносом объекта, а также предполагает взаимодействие с различными компетентными органами по поводу производства таких работ. Все вышеперечисленные виды работ являются элементами, входящими в инвестиционно-строительный процесс (далее - ИСП).

Исследования в области ИСП не позволяют дать однозначное определение данного процесca.

Так Ю.В. Аникин определяет ИСП как последовательную совокупность этапов достижения целей инвестирования путем реализации инвестиционных проектов в области создания или изменения объектов недвижимости. Причем инвестиционно-строительный проект (далее проект), по Ю.В. Аникину, является ограниченным временными рамками инвестиционным предприятием, направленным на создание нового объекта недвижимости, наличие и использование которого необходимы для достижения целей инвестирования [1, с. 20].

При этом, по мнению В.И. Малахова, представляется крайне затруднительным сформулировать точную модель реализации проекта, так как на практике она представляет собой широкий набор контрактных взаимоотношений всех участников проекта. В настоящее время отсутствие четкого и системного процесса взаимодействия проектов является причиной того, что диалог участников ИСП «не имеет под собой не только общепринятой и однозначной базы восприятия одних и тех же терминов, но и общего системного осмысления процессов» [4].

На наш взгляд, следует отметить, что отсутствие системы в этом процессе, четко определенных механизмов, существенно осложняет и тормозит инвестиционно-строительный процесс, который схематично представлен на рис. 1.

Предложенная последовательность ИСП, однако, является, действительно, базовой, многие ее элементы имеют непрямую зависимость друг от друга, взаимосвязи переплетены и, конечно, на рис. 1. схема не в полной мере отражает взаимоотношения участников ИСП, от грамотного выстраивания которых зависит качество, скорость, рентабельность и эффективность всего проекта.

Мы хотим выделить проектную деятельность и остановиться на ее рассмотрении в рамках строительной отрасли, как этапа инвестиционно-строительного процесса.

Проектирование, или создание проектносметной документации, представляет собой также часть инвестиционно-строительного проекта, является главнейшей его составляющей, результатом интеллектуального труда большого количества высокопрофессиональных специалистов. 


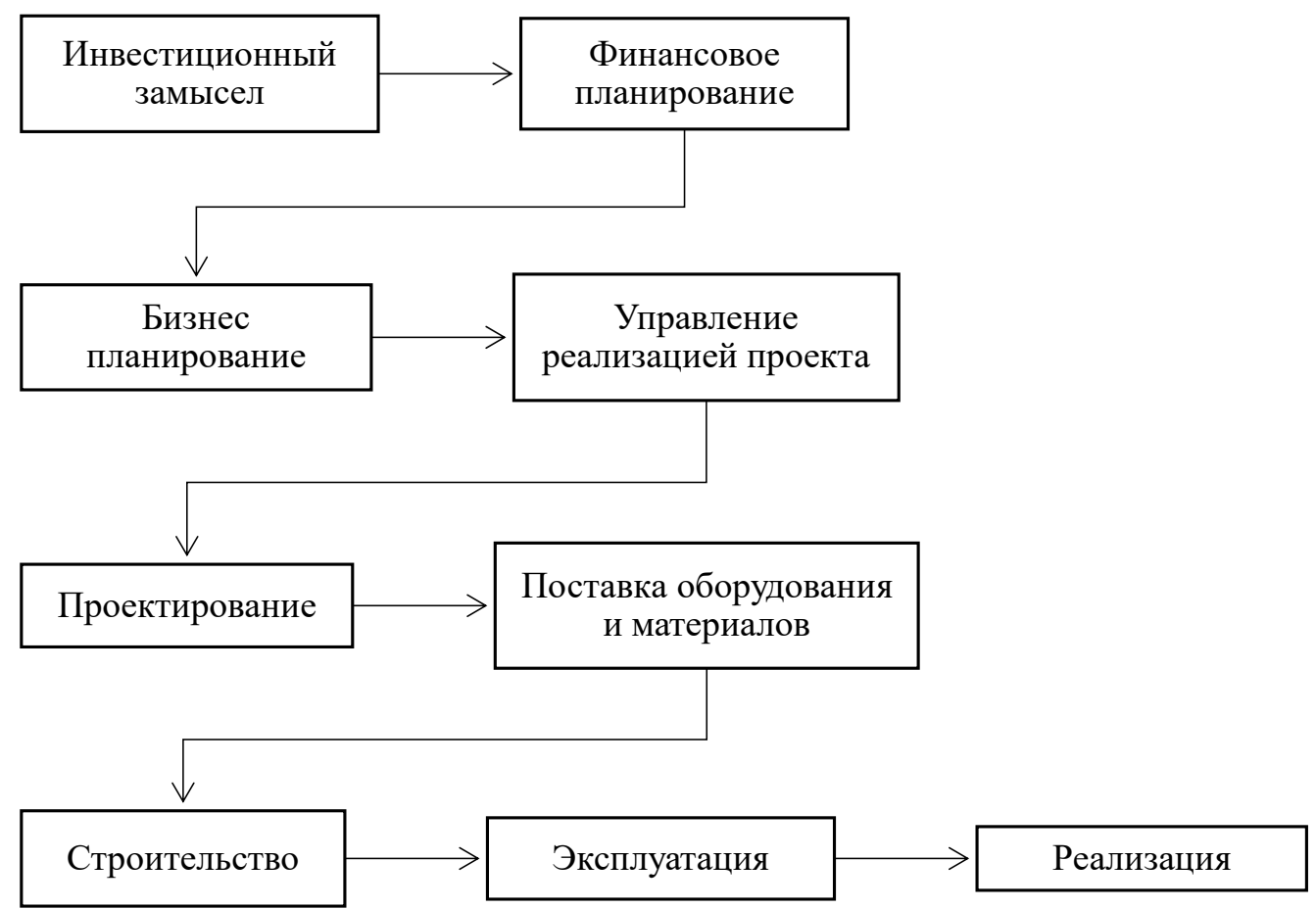

Рис. 1. Последовательность базового инвестиционно-строительного процесса [3].

Именно при создании проекта формируется архитектурный облик объекта недвижимости, который вписывается в окружающую застройку, становится на десятилетия частью городской среды. Кроме того, после завершения этапа проектирования в целом, определяются материальные, временные, финансовые затраты на реализацию инвестиционно-строительного проекта.

Чтобы точнее определить место и значимость проектирования в период инвестиционностроительного процесса, рассмотрим полномочия и обязательства субъектов ИСП (таблица 1):

Решения, которые принимаются в процессе реализации ИСП, на наш взгляд, можно разделить на три вида (таблица 2).

В данной статье мы рассматриваем модели взаимодействия субъектов ИСП в зависимости от источников инвестиций, бюджетных или коммерческих и схемы взаимоотношений участников проектной деятельности.

Модель № 1 может быть применена при создании объектов социальной инфраструктуры населенного пункта.

Инвестором и собственником построенного объекта выступает государство в лице уполномоченных органов субъекта федерации или местного самоуправления, бюджетные инвестиции предоставляются победителям конкурсного отбора на условиях 44 ФЗ [5].
Вторая модель реализуется в случае, если инвестором выступает коммерческая организация, инвестиции в строительство объекта формируются за счет привлеченных финансовых ресурсов банков, частных инвесторов или за счет собственных средств частного инвестора.

В этом случае юридическое лицо,- коммерческая организация, получившее от государства право на использование земельного участка на правах аренды, принимает на себя исполнение большинства управленческих функций. Имея договор аренды, это лицо является Застройщиком, привлекая финансовые ресурсы и управляя ими исполняет обязанности Заказчика. С целью минимизации затрат это лицо в большинстве случаев берет на себя осуществление функций Проектировщика и Генерального подрядчика.

В любом из рассмотренных вариантов реализации ИСП после принятия решения о необходимости создания, модернизации или реконструкции объекта недвижимости следует проектирование, которое есть начальная и важнейшая стадия ИСП и строительного производства в целом, без которой ни один проект не может быть реализован.

Создание необходимой и достаточной проектной документации для строительного процесса - основная задача проектных организаций. 
Таблица 1. Полномочия и обязательства субъектов инвестиционно- строительного процесса.

\begin{tabular}{|c|c|c|}
\hline № & Субъекты ИСП & Полномочия и обязательства \\
\hline \multirow[t]{7}{*}{1.} & Инвестор & $\begin{array}{l}\text { Принимает решение о целесообразности реализации проекта после } \\
\text { изучения его инвестиционных возможностей либо исполняет пору- } \\
\text { чение высшего органа управления, уже принявшего такое решение, } \\
\text { утверждает бюджет, обеспечивает проектирование и строительство } \\
\text { финансовыми ресурсами. }\end{array}$ \\
\hline & Заказчик & $\begin{array}{l}\text { Осуществляет управление и контроль над распределением финансов, } \\
\text { проектированием и строительством объекта в целом. В полномочия } \\
\text { заказчика входит: технико-экономическое обоснование капитальных } \\
\text { вложений, получение технических условий присоединения к инженер- } \\
\text { ным сетям, получение заключения государственной экспертизы ПСд, } \\
\text { утверждение стоимости строительства и, как результат, сдача объекта } \\
\text { в эксплуатацию или выход промышленного предприятия на проект- } \\
\text { ную мощность, реализация строительной продукции }\end{array}$ \\
\hline & Застройщик & $\begin{array}{l}\text { Обладает на праве собственности земельным участком. В случаях, ког- } \\
\text { да заказчик и застройщик не одно лицо, заказчик получает у застрой- } \\
\text { щика участок под застройку на условиях длительной аренды. }\end{array}$ \\
\hline & Проектная организация & $\begin{array}{l}\text { Проводит на основании заключенного договора с заказчиком изыска- } \\
\text { тельские работы, разрабатывает проектно-сметную документацию } \\
\text { (ПСд), в т.ч. формирует основные архитектурные и конструктивные } \\
\text { решения, подбирает оборудование, формирует стоимость строитель- } \\
\text { ства, получает положительное заключение государственной эксперти- } \\
\text { зы, ведет авторский надзор над строительством. }\end{array}$ \\
\hline & Подрядчик & $\begin{array}{l}\text { Выполняет работы по строительству объекта, согласно условиям за- } \\
\text { ключенного с заказчиком договора, полученной ПСД и существующим } \\
\text { строительным нормам и правилам }\end{array}$ \\
\hline & $\begin{array}{l}\text { Поставщики оборудования } \\
\text { и материалов }\end{array}$ & $\begin{array}{l}\text { Обеспечивают поставку материалов и оборудования через заказчика } \\
\text { или напрямую подрядчику в объеме, определенном ПСД. }\end{array}$ \\
\hline & $\begin{array}{l}\text { Собственник (пользователь) } \\
\text { объекта (инвестор) }\end{array}$ & Эксплуатирует объект, передаваемый ему заказчиком \\
\hline
\end{tabular}

Таблица 2. Структура принимаемых решений в рамках реализации инвестиционно-строительного процесса

\begin{tabular}{|c|c|c|}
\hline \multicolumn{2}{|c|}{ Решения } \\
\hline Управленческие & Финансовые & Технические \\
\hline Инвестиционный замысел & $\begin{array}{c}\text { Технико-экономическое } \\
\text { обоснование }\end{array}$ & $\begin{array}{c}\text { Инженерно-технические } \\
\text { изыскания }\end{array}$ \\
\hline \multicolumn{2}{|c|}{ Бизнес-планирование } & $\begin{array}{c}\text { Расчет нагрузок и получение ТУ } \\
\text { на присоединение к инженерным } \\
\text { сетям и др. }\end{array}$ \\
\hline $\begin{array}{c}\text { Утверждение финансового источ- } \\
\text { ника }\end{array}$ & $\begin{array}{c}\text { Обоснование и определение } \\
\text { сметной стоимости строительства, } \\
\text { объемов финансирования проекта }\end{array}$ & $\begin{array}{c}\text { Ррозработка объемно- } \\
\text { ющианстенных решений, влия- } \\
\text { юе облик застройки. }\end{array}$ \\
\hline $\begin{array}{c}\text { Управление реализацией проекта } \\
\text { на всех его этапах }\end{array}$ & $\begin{array}{l}\text { Обеспечение финансовыми ресур- } \\
\text { принятие всех технических реше- } \\
\text { ний в рамках разработки Пд }\end{array}$ \\
\hline
\end{tabular}




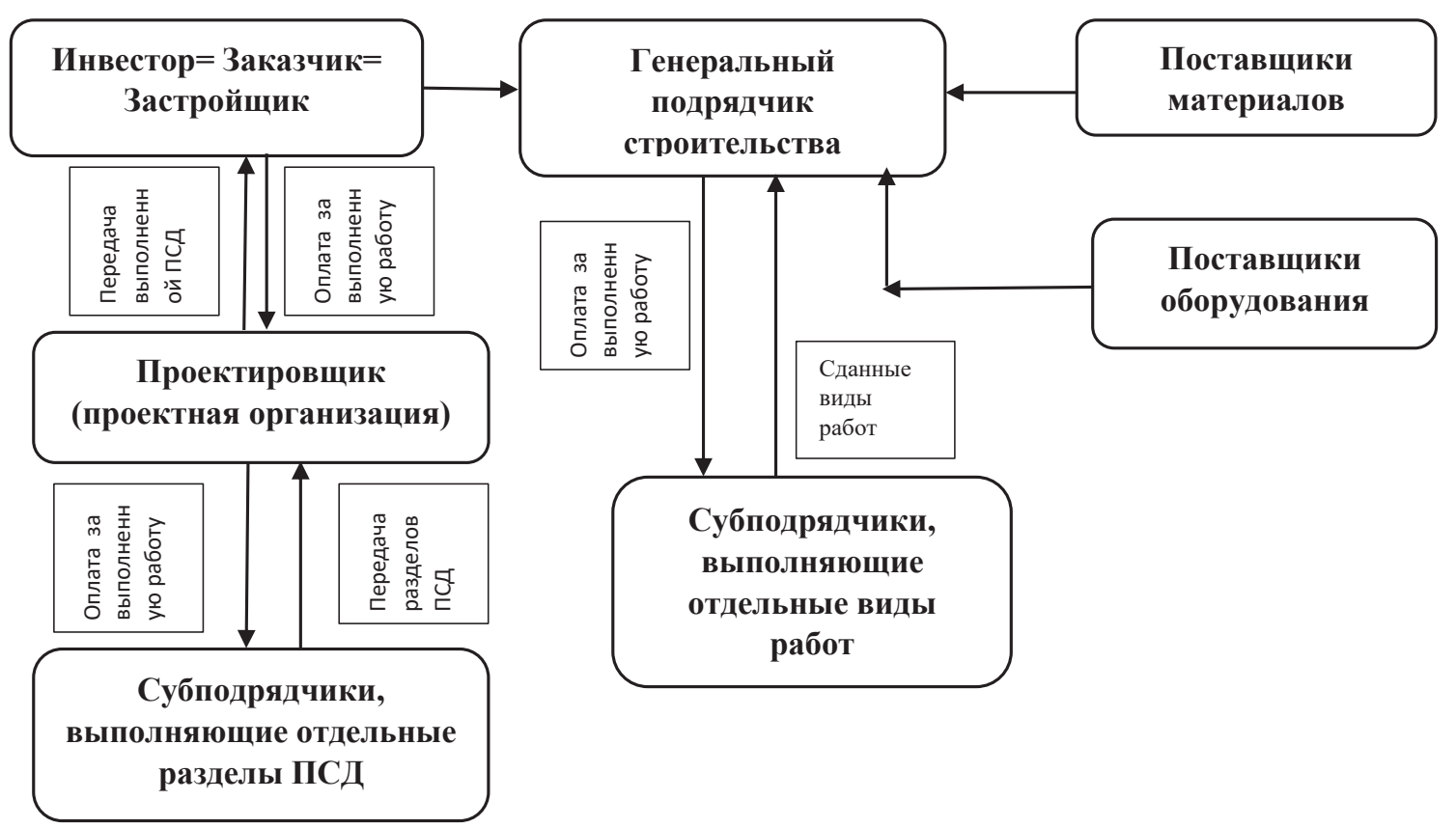

Модель 1. Субъекты ИСП и их взаимодействие при бюджетном финансировании.

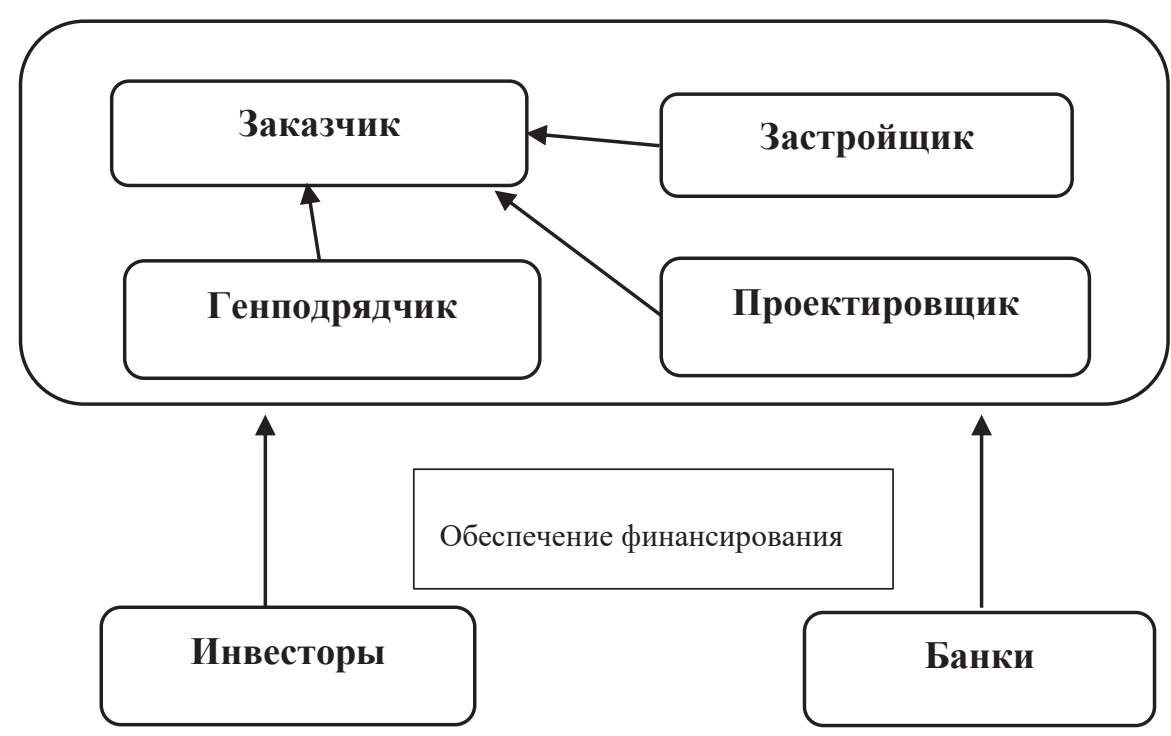

Модель 2. Субъекты ИСП и их взаимодействие при финансировании строительства за счет внебюджетных средств.

Определение проектной документации дает Градостроительный кодекс Российской Федерации. Он формулирует проект как документацию, в которой содержатся текстовые и графические материалы, формирующие решения для обеспечения строительства объектов, их реконструкции и/или капитального ремонта, таких как ар- хитектурные, функционально-технологические, конструктивные и инженерно-технические [2].

Результат разработки сметной документации дает возможность инвестору определить стоимость строительства объекта, при этом продолжительность и эффективность строительства, технический уровень объекта и экономические 
показатели в большей степени зависят от принятых проектных решений.

Для проверки безопасности принятых проектных решений и определения достоверности сметной стоимости строительства заказчики обязуют подрядные организации проходить государственную или негосударственную экспертизу разработанной проектной и/или сметной документации.

Роль проектирования в ИСП, и, в частности, в строительной отрасли сложно переоценить.
В широком смысле проектирование является мощным рычагом, позволяющим создавать благоприятные условия для производственной, социальной и культурной деятельности людей. Именно с проектирования начинается формирование градостроительного облика городов и поселков, определяются территории развития промышленности и гражданского строительства, общественные пространства и среда обитания жителей.

\section{Библиографический список}

1. Аникин Ю.В. Проектное дело в строительстве: [учеб. пособие] / Ю. В. Аникин, Н.С. Царев; [науч. ред. В.И. Аксенов]; М-во образования и науки Рос. Федерации, Урал. федер. ун-т - Екатеринбург: Изд-во Урал. ун-та, 2015.- $124 \mathrm{c}$.

2. Градостроительный кодекс Российской Федерации от 29.12.2004 № 190 -ФЗ (ред. от 25.12.2018). Статья 48. Архитектурно- строительное проектирование. [Электронный ресурc]. URL: http://www.consultant.ru/ document/cons_doc_LAW_51040/b884020ea7453099ba8bc9ca021b84982cadea7d/ (дата обращения: 15.08.2019)

3. Малахов В.И. Контрактные модели реализации инвестиционно- строительных проектов [Электронный ресурс] // Корпоративный менеджмент: сайт. URL: http://www.cfin.ru/investor/contract_models.shtml (дата обращения: 18.10.2019).]

4. Малахов В.И. Контрактное моделирование инвестиционно-строительных проектов 2013 [Электронный реcypc].URL: https://www.cfin.ru/itm/bpr/project_lifecycle_process.shtml].

5. О контрактной системе в сфере закупок товаров, работ, услуг для обеспечения государственных и муниципальных нужд: Федеральный закон от 05.04.2013 № 44-Ф3 (ред. от 31.12.2017). Доступ из справ.- правовой системы «КонсультантПлюс» (дата обращения: 12.08.2019). 